\title{
Uric Acid Detection Using Quartz Crystal Microbalance Coated with Uricase Immobilized on ZnO Nanotetrapods
}

\author{
Xiaohua Wang*, Yinglong Yao ${ }^{1}$, Jian Zhang*, Ziqiang Zhu and Jianzhong Zhu \\ Department of Electrical Engineering, East China Normal University, \\ 500 Dongchuan Road, Shanghai 200241, China \\ ${ }^{1}$ Department of Thoracic and Cardiovascular Surgery, 150 Central Hospital, \\ Luoyang 471031, China
}

(Received July 31, 2007; accepted May 2, 2008)

Key words: ZnO nanotetrapods, uricase, uric acid, quartz crystal microbalance, biosensor, immobilization

The sensing properties of uricase immobilized on $\mathrm{ZnO}$ nanotetrapods for uric acid detection were studied using a quartz crystal microbalance (QCM). The ZnO nanotetrapods were synthesized by thermally evaporating high-purity zinc pellets (99.999\%) at $900^{\circ} \mathrm{C}$ in air. The sensors were constructed by distributing the $\mathrm{ZnO}$ nanotetrapods onto the electrode surfaces of the QCM at room temperature. Then uricase was directly immobilized on the $\mathrm{ZnO}$ nanotetrapods for uric acid detection. Our results indicated that this QCM sensor shows high sensitivity $\left(10^{6} \mathrm{~Hz} / \mathrm{mol} / \mathrm{L}\right)$ for uric acid detection in a liquid environment. The frequency response of the sensor showed a linear $(r=0.99872)$ dependence on uric acid concentration ranging from $5.0 \times 10^{-6}$ to $1.0 \times 10^{-3} \mathrm{~mol} \mathrm{~L}^{-1}$ with a detection limit of $2.0 \times 10^{-6} \mathrm{~mol} \mathrm{~L}^{-1}$. All the results demonstrated that the one-dimensional $\mathrm{ZnO}$ structure is a good material for biosensor application.

\section{Introduction}

Uric acid is an end product of purine derivatives in human metabolism. Its determination is of paramount importance in the diagnosis of diseases caused by disorders in purine biosynthesis and/or purine catabolism, such as gout, hyperuricemia, and Lesch-Nyhan syndrome. ${ }^{(1-3)}$ From the literature, various methods such as electrochemical, spectrophotometric, chemiluminescence (CL) and high-performance liquid chromatography (HPLC) methods ${ }^{(4-9)}$ have been reported for the analysis of uric acid.

*Corresponding authors: e-mail: xhwang@ee.ecnu.edu.cn, jzhang@ee.ecnu.edu.cn 
Since the earliest quartz crystal microbalance (QCM) biosensor was reported in 1972, the device has been widely used for biological analysis, clinical diagnosis, and environmental monitoring. ${ }^{(10,11)}$ The QCM has been known as a surface-sensitive and analytical device capable of the on-line monitoring of interfacial reactions and thin film deposition. The liquid cell configuration of the devices make them suitable for the realtime study of bioaffinity reactions in relevant solution conditions.

Recent advances in biocompatible nanomaterials and biotechnology open a promising field toward the development of third-generation biosensors. ${ }^{12,13)}$ Nanomaterials have unique advantages in an immobilized enzyme. They can maintain the activity of the enzyme due to the desirable microenvironment, and enhance the direct electron transfer between the enzyme's active sites and the electrode. However, the majority of the nanomatrial-modified biosensors reported previously were based on colloidal gold nanoparticles. ${ }^{(13-16)} \mathrm{ZnO}$ is a semiconductor with a wide direct band gap of $3.37 \mathrm{eV}^{(17-19)}$ and also has great potential in application for sensor construction in terms of its biomimetic properties. ${ }^{(19-21)}$ The immobilization of cytochrome $\mathrm{c}$ on nanoporous $\mathrm{ZnO}$ film has already been reported. $\mathrm{ZnO}$ with a high isoelectric point (IEP) (IEP 9.5) should be suitable for the adsorption of low-IEP proteins or enzymes. ${ }^{(22)}$

In this paper, we present a way to analyze uric acid using a QCM device. Firstly, $\mathrm{ZnO}$ nanotetrapods were immobilized on the gold electrode of a QCM. Then uricase (IEP 4.3), which catalyzes the oxidation of uric acid to allantoin, carbon dioxide, and hydrogen peroxide, was immobilized on $\mathrm{ZnO}$ nanotetrapods by a drop coating process. The modified QCM device was used to test different concentrations of uric acid. The experiment indicated that the QCM device can be used for uric acid detection and that $\mathrm{ZnO}$ nanotetrapods are a good candidate for biosensor application.

\section{Experiment}

\subsection{Preparation and characterization of $\mathrm{ZnO}$ nanotetrapods}

$\mathrm{ZnO}$ nanotetrapods were synthesized by the thermal evaporation of metallic zinc pellets (purity: $99.999 \%$ ) at $900^{\circ} \mathrm{C}$ under air ambient. A fused-quartz tube was inserted into a horizontal tube furnace and heated up to $900^{\circ} \mathrm{C}$. A quartz plate holding a few spherical $\mathrm{Zn}$ pellets of about $3 \mathrm{~mm}$ diameter was pushed into the tube. After heating for about 2 min, a dazzling cluster was observed on top of the zinc pellets and a white fog appeared in the tube. The quartz plate was pulled out from the tube furnace slowly. A white precipitate was found on the surface of the plate and was collected for future use.

The product was characterized using various techniques, such as scanning electron microscopy (SEM), transmission electron microscopy (TEM), and X-ray diffraction (XRD), and the results demonstrated that it had the nanotetrapod configuration. ${ }^{(23-26)}$

\subsection{Apparatus}

SEM images were recorded using a JSM-5610LV electron microscope. The phase and crystallinity were examined by XRD analysis using a Bruker D8 ADVANCE $\mathrm{X}$-ray diffractometer with $\mathrm{CuK} \alpha$ radiation $(\lambda=0.15405 \mathrm{~nm})$. Infrared spectra were collected with a Nicolet Nexus 670 Fourier transform infrared spectroscopy (FT-IR) 
spectrophotometer with single-reflection attenuated total reflection (ATR) accessories. The crystal material was Ge and the spectral range was from $4000-675 \mathrm{~cm}^{-1}$.

The system used for QCM measurement is shown in Fig. 1. Nine megahertz ATcut QCMs with a gold electrode (with an area of $0.2 \mathrm{~cm}^{2}$ ) were used for this study. For liquid-phase measurement, the crystals were clamped between two Plexiglas blocks with Neoprene O-ring seals. During detection, only one of the crystal electrode surfaces was exposed to the detected solutions. We call this instrument the QCM cell in this paper. After the QCM cell was installed, it was put into a vessel containing the buffer solution for measurement. A pipette was used to add a given amount of sample (such as uricase or uric acid) to the vessel. The frequency measurements were performed at room temperature $\left(\sim 25^{\circ} \mathrm{C}\right)$ using a quartz analyzer (QCA 917, EG\&G Seiko). The data obtained were sent to a computer for recording and analysis. The configuration of the liquid handling system is schematically described elsewhere. ${ }^{(27)}$

\subsection{Reagents}

Uricase (4.2 units/mg) (one unit of uricase will oxidize $1.0 \mu \mathrm{mol}$ of uric acid into allantoin at $25^{\circ} \mathrm{C}$ ) and uric acid (99\% purity) were purchased from Sigma Chemical Co. Other reagents were of analytical grade. The phosphate-buffered saline (PBS) used is composed of $137 \mathrm{mM} \mathrm{NaCl}, 2.7 \mathrm{mM} \mathrm{KCl}, 8.0 \mathrm{mM} \mathrm{Na}_{2} \mathrm{HPO}_{4}$, and $1.5 \mathrm{mM} \mathrm{KH}_{2} \mathrm{PO}_{4}(\mathrm{pH}$ 7.2). Uric acid solution was obtained by dissolving $3.34 \mathrm{mg}$ of uric acid in $5 \mathrm{ml}$ of PBS under an ultrasonic agitating condition. In order to cast the uricase onto the $\mathrm{ZnO}$ nanotetrapodmodified QCM sensor, $7.2 \mathrm{mg}$ of uricase was dissolved in $1 \mathrm{ml}$ of PBS solution under the ultrasonic agitating condition.

\subsection{Preparation of ZnO-nanotetrapod-modified QCM}

Prior to the experiment, the QCMs were cleaned with piranha solution $\left(3: 1 \mathrm{H}_{2} \mathrm{SO}_{4}\right.$ : $30 \% \mathrm{H}_{2} \mathrm{O}_{2}$ ). (Note: This is a dangerous cleaning solution and care must be taken in handling it.) After rinsing with a large amount of deionized (DI) water, the crystals were blow-dried with highly pure nitrogen. At this stage, the resonant frequency was recoded for reference.

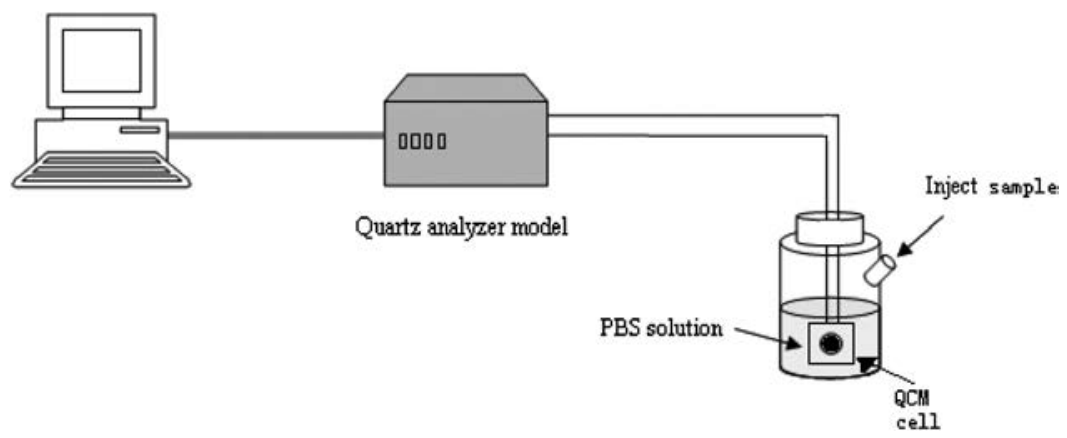

Fig. 1. Block diagram of testing system. 
A $\mathrm{ZnO}$ suspension was prepared by ultrasonically dispersing $\mathrm{ZnO}$ nanotetrapods in ethanol for $48 \mathrm{~h}$ until a stable solution was obtained. The suspension was then applied on the surface of the crystals. The crystals were placed horizontally to ensure a uniform thin film distribution. After that, the crystals were allowed to stand at $100^{\circ} \mathrm{C}$ for $\sim 2 \mathrm{~h}$ to guarantee the complete evaporation of ethanol and the formation of thin films. This could also be verified by the absence of any further shift in resonant frequency. The frequency shifts were measured to evaluate the thickness of the coated layers based on the Sauerbrey equation:

$$
\Delta f=-2.26 \times 10^{-6} f^{2} \Delta m / A,
$$

where $f(\mathrm{MHz})$ is the fundamental frequency of the unloaded piezoelectric crystal, $\Delta m$ (g) is the mass loading on the surface of the crystal, and $A\left(\mathrm{~cm}^{2}\right)$ is the surface area of the electrode. The thickness of the thin films of $\mathrm{ZnO}$ nanotetrapods was determined by assuming the density of the $\mathrm{ZnO}$ nanotetrapods to be $5.6 \mathrm{~g} / \mathrm{cm}^{3}$ (the value of the bulk material). In our experiment, after the crystals were cleaned, both sides of the QCM electrode were coated with $\mathrm{ZnO}$ nanotetrapod solution to form thin films of 90-100 nm thickness according to eq. (1).

\subsection{Uricase immobilization and uric acid detection}

The uricase/ZnO biosensor was constructed by casting the uricase (mentioned in $\S 2.3$ ) on the ZnO-nanotetrapod-modified QCM. Each time $10 \mu \mathrm{l}$ of uricase solution was dropped on the ZnO-nanotetrapod-modified QCM. After dropping, the QCM was dried using a hair drier. A similar step was repeated until a total of $1 \mathrm{ml}$ of uricase was cast on the $\mathrm{ZnO}$-nanotetrapod-modified QCM. It is known that uricase can be electrostatically bonded with $\mathrm{ZnO}$ film. Before each application, the QCM sensors were soaked in PBS for $5 \mathrm{~h}$ to remove the loosely bound or unbound enzyme molecules. The uricase/ZnO QCM cell was put into the vessel and then $5 \mathrm{ml}$ of PBS solution was introduced. Uric acid was also introduced into the vessel to prepare a $5.0 \times 10^{-6}-1.0 \times 10^{-3} \mathrm{~mol} / \mathrm{L}$ uric acid solution. The uricase/ZnO QCM sensors were stored at $4^{\circ} \mathrm{C}$ if they were not used immediately.

\section{Results and Discussion}

\subsection{Characterization of $\mathrm{ZnO}$ nanotetrapods}

Figure 2(a) shows SEM images of the $\mathrm{ZnO}$ nanotetrapods deposited on the QCM substrate, which indicate the presence of many nanotetrapods with a relatively narrow diameter distribution (mean diameter: about $20 \mathrm{~nm}$ ). The crystals were tetrapod-shaped; four needles are tetrahedrally arranged to combine at the center.

When uricase was immobilized onto the $\mathrm{ZnO}$ nanotetrapod surfaces, the SEM image changed (Fig. 2(b)). The procedure for immobilizing the uricase was as follows. Firstly, we cast the uricase (mentioned in $\S 2.3$ ) on the ZnO-nanotetrapod-modified QCM. Secondly, the QCM sensors were soaked in PBS for $5 \mathrm{~h}$ to remove the loosely bound or unbound enzyme molecules after the uricase casting. Thirdly, the sensor was rinsed 


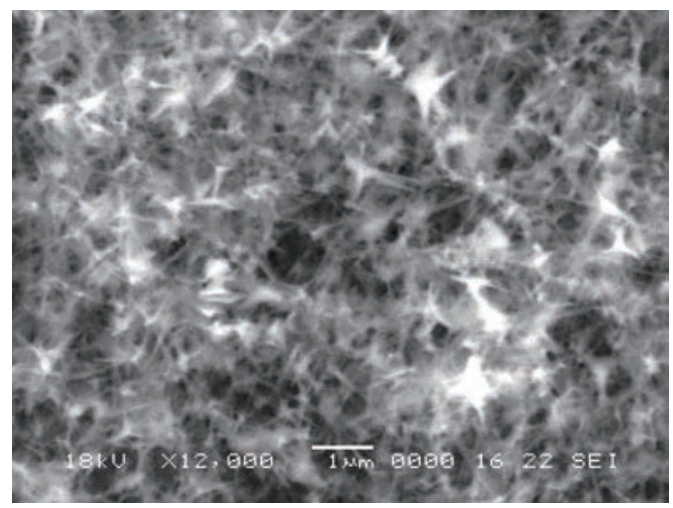

(a)

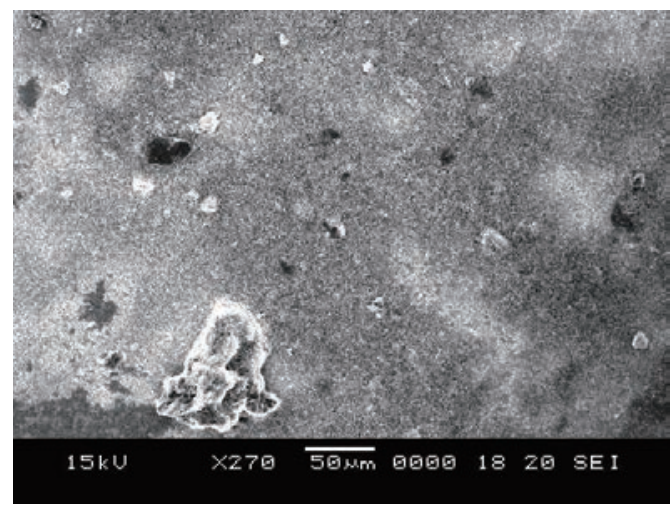

(b)

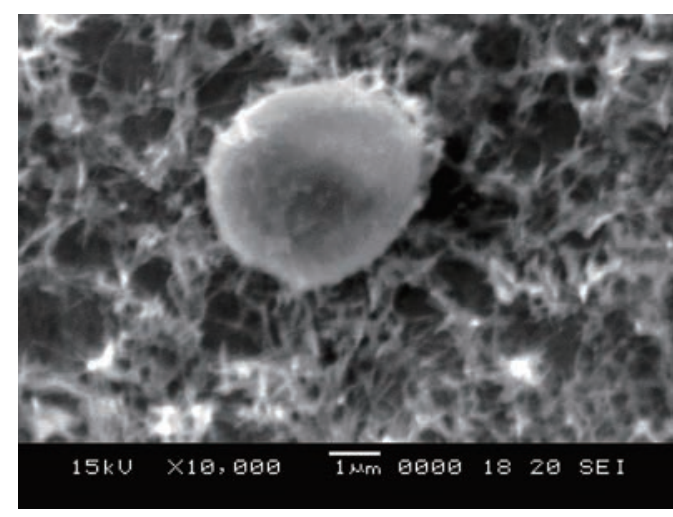

(c)

Fig. 2. SEM images of QCM surface (a) ZnO-nanotetrapod-modified QCM (b) uricase immobilization on $\mathrm{ZnO}$ nanotetrapod film, (c) one of the uricase molecular clusters.

by DI water and dried. Then we took an SEM photo and got Fig. 2(b). In Fig. 2(b), the aggregates of the trapped enzyme molecules existed regularly and an islandlike structure was observed. The islandlike structure was a cluster of uricase molecules well attached on the $\mathrm{ZnO}$ layer.

Figure 2(c) shows one of the immobilized uricase molecule clusters. This structure may facilitate the specific reaction between the substrate and uricase and results in efficient uric acid detection.

The X-ray diffraction spectrum of the $\mathrm{ZnO}$ nanotetrapods deposited on the silicon substrate is shown in Fig. 3. This figure only shows the $\mathrm{ZnO}$ phases, while the silicon phase $\left(2 \theta=68.52^{\circ}(400)\right.$ plane) was cut off because of its high peaks. 


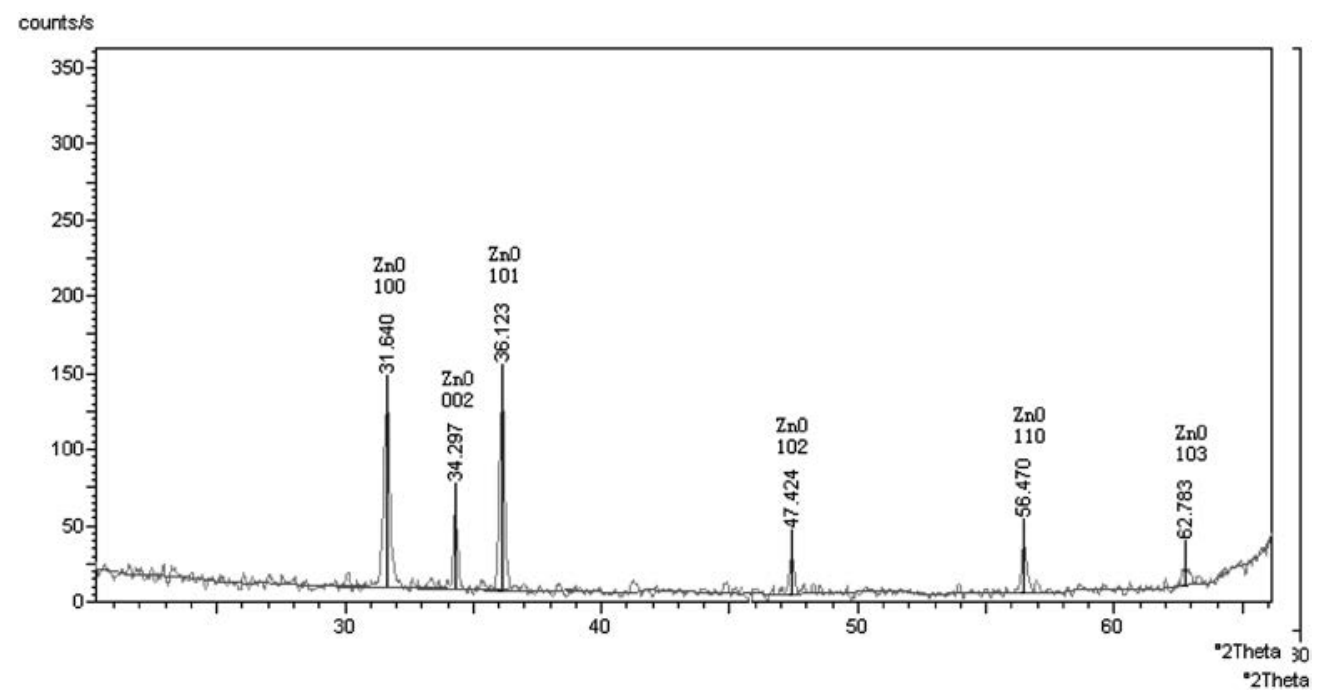

Fig. 3. XRD results for ZnO nanotetrapods coated on Si substrate.

\subsection{Sensor stability}

Figure 4 shows the time-dependent frequency response of the uricase/ $\mathrm{ZnO}$ nanotetrapod QCM sensors operating in PBS solution. It was observed that the frequency shift was less than $\sim 1 \mathrm{~Hz}$ within 60 min indicating a stable process. According to this result, it was confirmed that the sensor is stable. During the experiment, the criterion for a stable response is that the frequency change is no more than $1 \mathrm{~Hz}$ within 3 min. All the data were noted according to this criterion.

The inset figure shows that the sensor would operate under a stable condition after 1 min. This indicates that the response of the sensor was fast.

\subsection{Selectivity of the sensor}

The characterization of uricase immobilization on the $\mathrm{ZnO}$-nanotetrapod-modified surface was studied, as shown in Fig. 5. The abscissa of the figure was the injected volume of uricase solution $(\S 2.3)$ using a controllable pipette. From the figure, it was found that the frequency decreased. When the uric acid was introduced in the PBS solution to replace the uricase, no frequency shift was observed. This result indicated that $\mathrm{ZnO}$ can adsorb uricase well but cannot adsorb uric acid.

\subsection{Uricase immobilization and uric acid detection}

Figure 6 shows the relationship between the frequency shift of the uricase/ZnO biosensor and the detected uric acid concentration (in the range from $5.0 \times 10^{-6}$ to $1.0 \times 10^{-3} \mathrm{~mol} / \mathrm{L}$ ). From the figure, it can be observed that the response curve can be divided into two parts; for uric acid in the range from $5.0 \times 10^{-6}$ to $1.0 \times 10^{-3} \mathrm{~mol} / \mathrm{L}$, the calibrated response to uric acid was linear $(r=0.99872)$. The frequency sensitivity is about $106 \mathrm{~Hz} / \mathrm{mol} / \mathrm{L}$. 


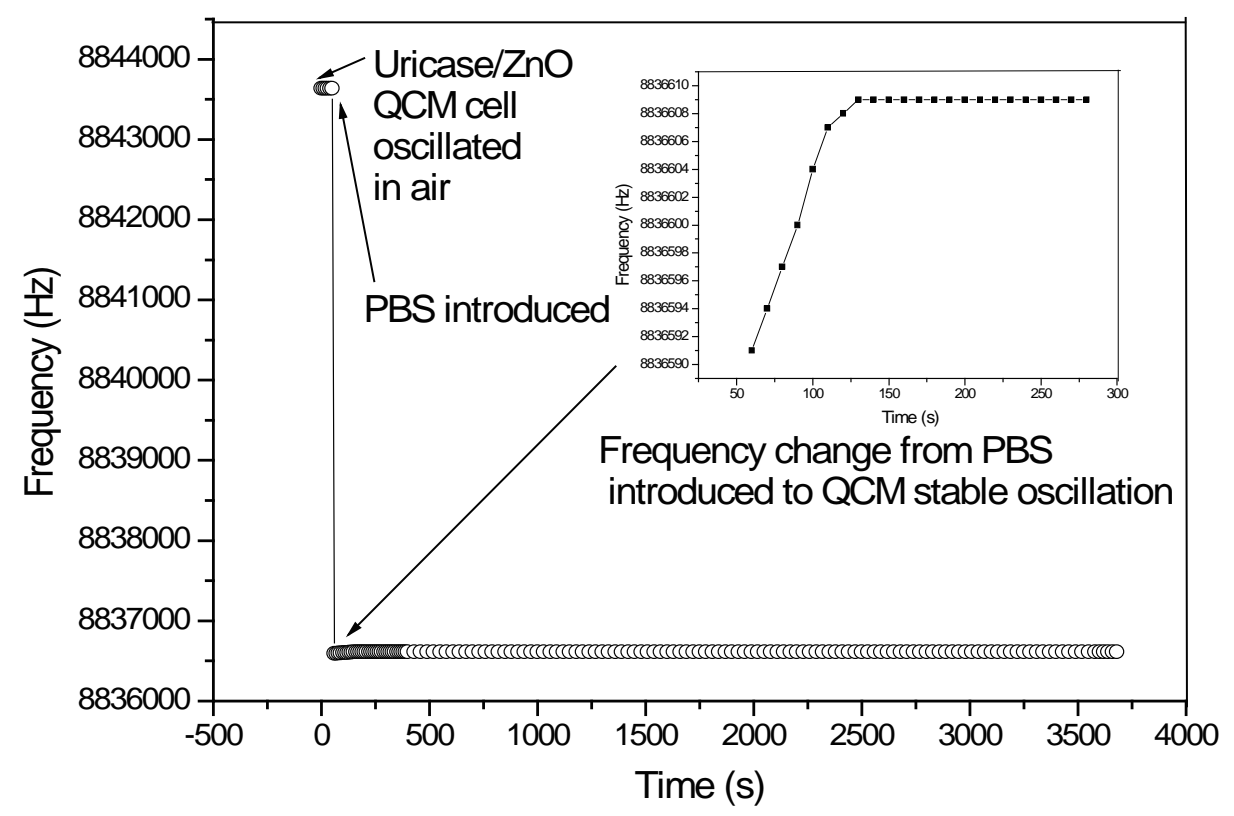

Fig. 4. Time-dependent frequency response of the sensor in PBS solution. Inset: frequency range (vertical axis) from $8836610 \mathrm{~Hz}$ to $8836590 \mathrm{~Hz}$, time range (horizontal axis) from 0 to $300 \mathrm{~s}$.

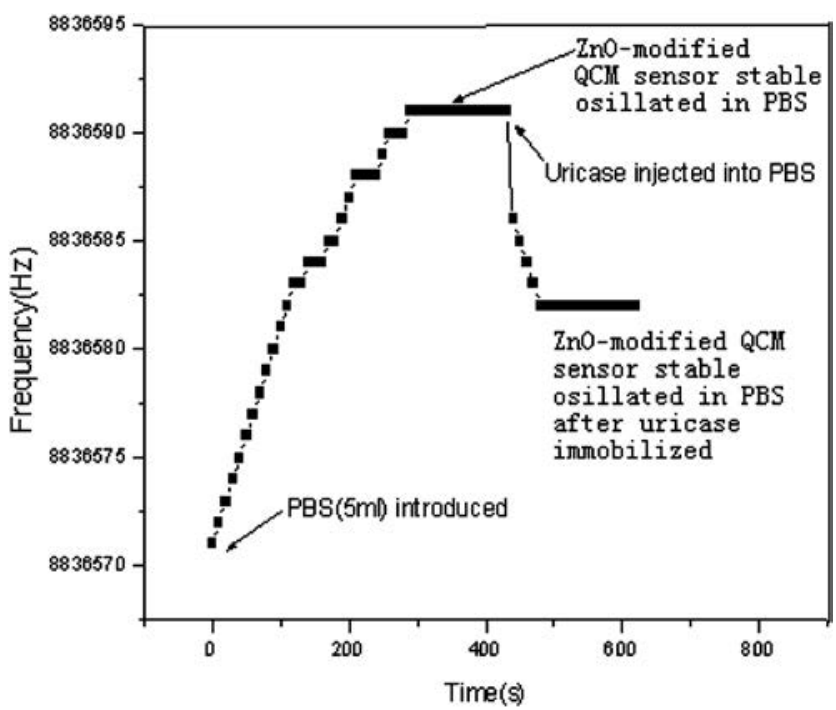

Fig. 5. Characterization of uricase immobilization on $\mathrm{ZnO}$-nanotetrapod-modified surface. 


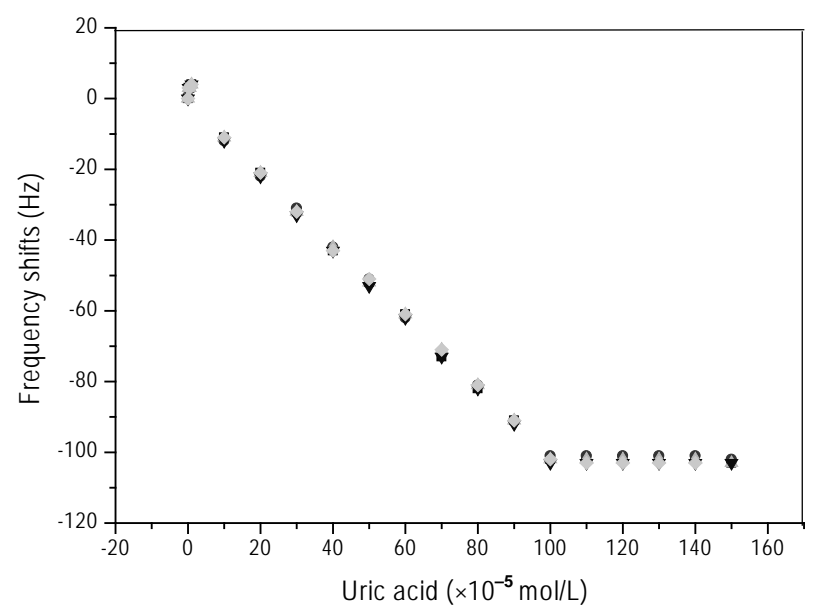

Fig. 6. Frequency response of the sensor when the concentration range of uric acid was from $5.0 \times 10^{-6}$ to $1.0 \times 10^{-3} \mathrm{~mol} / \mathrm{L}$.

When the concentration of uric acid further increased, the response of the sensor became saturated. All the data in Fig. 5 were obtained from five independent experiments with both increasing and decreasing uric acid concentrations.

Figure 7 shows the time-dependent frequency response of the uricase/ZnO biosensor in the entire detection process. No considerable difference was found with the change in the concentration $\left(5.0 \times 10^{-6}\right.$ to $\left.1.0 \times 10^{-3} \mathrm{~mol} / \mathrm{L}\right)$ of uric acid.

\subsection{FTIR results}

Figure 8 shows single-reflection FTIR spectra that prove that the uric acid is oxidized. In the figure, curve (a) represents the spectra of uricase immobilization on $\mathrm{ZnO}$-modified QCM and curve (b) is the spectra of the ZnO-nanotetrapod-modified QCM after uric acid oxidation. From the figure, it can be observed that a difference exists between curves (a) and (b). The absorption region from 650 to $1500 \mathrm{~cm}^{-1}$ generally represents the fingerprint region of $\mathrm{ZnO}$. $\mathrm{ZnO}$ produced a band around $1027 \mathrm{~cm}^{-1}$ in curves (a) and (b). The absorption peak value around $3387 \mathrm{~cm}^{-1}$ can be assigned to the $\mathrm{N}-\mathrm{H}$ and $\mathrm{O}-\mathrm{H}$ bonds, $1677 \mathrm{~cm}^{-1}$ to the $\mathrm{C}=\mathrm{O}$ bond, and $1641 \mathrm{~cm}^{-1}$ to the $\mathrm{C}-\mathrm{H}$ bond in curve (b). All these bonds accord with the molecular formula of allantoin. This result showed that uric acid was oxidized by uricase and allantoin was the outcome of the reaction. Thus, the validity of the experiment was confirmed through the FTIR results.

\section{Discussion}

It is well-known that liquid-phase QCM responses are attributed to several factors, including mass uptake, density, and the viscosity of liquid samples, and the viscoelasticity of the molecular coating. ${ }^{(28)}$ We considered that one explanation of the mechanism was the mass change on the surface of the QCM. Uricase was highly immobilized on ZnO 


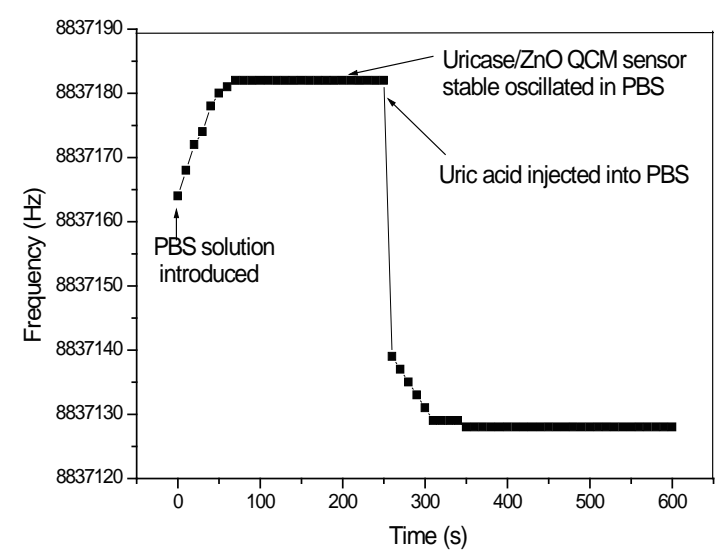

Fig. 7. Time-dependent frequency response of the sensor to PBS stability and uric acid $\left(5.0 \times 10^{-4} \mathrm{~mol} / \mathrm{L}\right)$ detection.

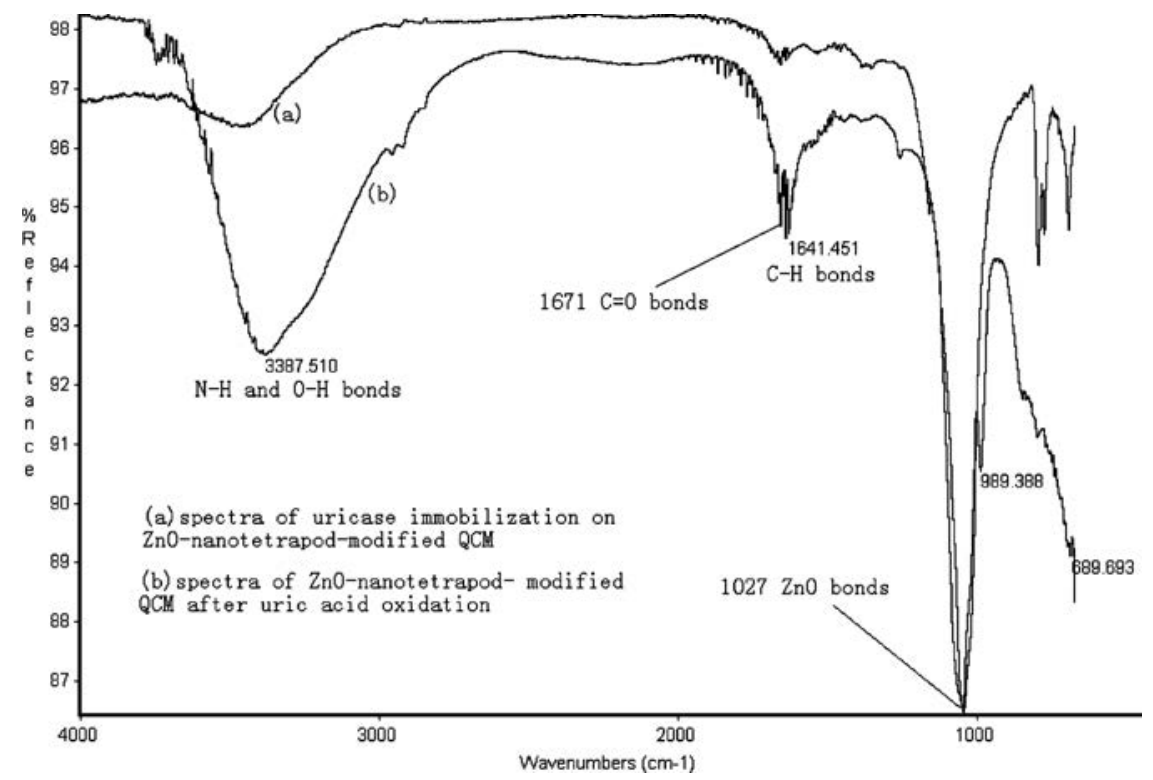

Fig. 8. Infrared spectra of the surface using single-reflection ATR FTIR. Curve a: spectra of uricase immobilization on ZnO-nanotetrapod-modified QCM, curve b: spectra of $\mathrm{ZnO}$ nanotetrapod-modified QCM after uric acid oxidation.

nanotetrapods while it could not be immobilized on the gold electrode in our experiment. When uricase was immobilized on $\mathrm{ZnO}$ nanotetrapods, the frequency decreased. After the reaction, the frequency decreased continuously because allantoin was produced and immobilized on $\mathrm{ZnO}$ nanotetrapods. We will continue to study the mechanism in the future. 


\section{Conclusion}

In our laboratory studies, uric acid biosensors based on a QCM coated with thinfilm $\mathrm{ZnO}$ nanotetrapods were developed. The sensors showed excellent stability and sensitivity. The observed attractive features might be attributed to the unique conducting $\mathrm{ZnO}$ nanotetrapods, which provided a favorable microenvironment for enzyme immobilization. We hope that this study will widen the use of quartz crystals in bioscience because QCM-based sensors have various potential applications such as environmental monitoring sensors, water pollutant sensors, and biosensors.

\section{Acknowledgements}

This paper was supported by the Research program of the China Ministry of Science and Technology (No.2006CB932802) and the National Natural Science Foundation of China (No.60672002).

\section{References}

1 B. Ullman, M. B. Cohen, D. W. Martin and M. A. Wormsted: Proc. Natl. Acad. Sci. 79 (1982) 5127.

2 H. Yamanaka, R. Togashi, M. Hakoda, C. Terai, S. Kashiwazaki, T. Dan and N. Kamatani: Adv. Exp. Med. Biol. 431 (1998) 13.

3 I. H. Fox: Metabolism 30 (1981) 616.

4 J. M. Zen, J. J. Jou and G. Ilangovan: Analyst 103 (1998) 1345.

5 H.-C. Hong and H.-J. Huang: Anal. Chim. Acta 499 (2003) 41.

6 J. Wang, T. Golden and P. Tuzhi: Anal. Chem. 59 (1987) 740.

7 W. Peng, T. Li, H. Li and E. Wang: Anal. Chim. Acta 298 (1994) 415.

8 M. J. Stewart, P. I. Adriaenssens, D. R. Jarvie and L. F. Prescott: Ann. Clin. Biochem. 16 (1979) 89.

9 A. N. Papas, M. Y. Alpert, S. M. Marchese, J. W. Fitzgerald and M. F. Delaney: Anal. Chem. 57 (1985) 1408.

10 A. Shons, F. Dorman, J. Najarian and J. Biomed: Mater. Res. 6 (1972) 565.

11 J. Zhang, J. Q. Hu, F. R. Zhu, H. Gong and S. J. O’Shea: Sens. Actuators B 87 (2002) 159.

12 J. B. Jia, B. Q. Wang, A. G. Wu, G. G. Cheng, Z. Li and S. J. Dong: Anal. Chem. 74 (2002) 2217.

13 L. Gorton, A. Lindgren, T. Larsson, F. D. Munteanu, T. Ruzgas and I. Gazaryan: Anal. Chim. Acta 400 (1999) 91.

14 S. Q. Liu, J. H. Yu and H. X. Ju: J. Electroanal. Chem. 540 (2003) 61.

15 H. Y. Gu, A. M. Yu and H. Y. Chen: J. Electroanal. Chem. 516 (2001) 119.

16 Y. Xiao, H. X. Ju and H. Y. Chen: Anal. Biochem. 278 (2000) 22.

17 B. Liu and H. C. Zeng: J. Am. Chem. Soc. 125 (2003) 4430.

18 L. Guo, Y. L. Ji and H. B. Xu: J. Am. Chem. Soc. 124 (2002) 14864.

19 Z. R. Tian, J. A. Voigt, J. Liu, B. Mckenzie and M. J. Mcdermott: J. Am. Chem. Soc. 124 (2002) 12954.

20 G. Sberveglieri, S. Groppelli, P. Nelli, A. Tintinelli and G. Giunta: Sens. Actuators B 25 (1995) 588. 
21 F. Zhang, X. Wang, S. Ai, Z. Sun, Q. Wan, Z. Zhu, Y. Xian, L. Jin and K. Yamamoto: Anal. Chim. Acta 519 (2004) 155.

22 E. Topoglidis, A. E. G. Cass, B. O’Regan and J. R. Durrant: J. Electroanal. Chem. 517 (2001) 20.

23 X. Wang, J. Zhang and Z. Zhu: Appl. Surf. Sci. 252 (2006) 2404.

24 X. Wang, Y. Ding, J. Zhang, Z. Zhu, S. You, S. Chen and J. Zhu: Sens. Actuators B 115 (2006) 421.

25 X. Wang, J. Zhang, Z. Zhu and J. Zhu: Appl. Surf. Sci. 253 (2007) 3168.

26 X. Wang, J. Zhang, Z. Zhu and J. Zhu: Colloids Surf. A 276 (2006) 59.

27 Y.-K. Cho, S. Kim, Y. A. Kim, H. K. Lim, K. Lee, D. Yoon, G. Lim, Y. E. Pak, T. H. Ha and K. Kim: J. Colloid Interface Sci. 278 (2004) 44.

28 X. Su and J. Zhang: Sens. Actuators B 100 (2004) 309. 